\title{
RADYOKARBON ILE YAŞLANDIRMADA ÖRNEKLIKLERI SEÇME ÖLÇÜTLERI
}

\author{
J. EVIN \\ Çeviren: Işı YALÇINKAYA
}

\section{Özet:}

Araştırıcı, radyokarbon ile yaşlandırılmaya ayrılmış bir örnekliğin değerini oluşturan şeyi, bütün olurlu farkh görünümler altında incelerken jeolojik ve arkeolojik yataklardan elde edilmiş karbonlu tüm materyel tiplerini de gözden geçirir. Yine örnekliğin en iyi şekilde seçilebilmesi için bazı arazi ilkelerini de hatırlatır ve sonuçta bunlar için bir çeşit yeğleme düzeni verir.

\section{Giriş:}

Fransız jeolojik ve arkeolojik yatakları için yapılmış tüm yaşlandırmaların çeşitli özetleyici tabloları son yıllarda yayınlanmıştır. (Delibrias et Evin, 1974-1975; Delibrias et al., I976). Ve yine bir çok konu üzerinde yapılmış bazı sentez çalısmaları göstermiş̧ir ki, $\mathrm{C}_{14}$ kronolojisi her nekadar birkaç evre ve birkaç yöre için yeterince kurulmuşsa da, gene de $\mathrm{C}_{14}$ salt kronolojisinin karşllılı bağıntılarının olurlu olabilmesi için geriye yapılacak pek çok iş kalmaktadır (Evin, 1977). $\mathrm{C}_{14}$ 'ün, tüm yeni kazılarda, elden geldiğince yaygın bir biçimde, kullanılmıs olması istenilecek bir husustur. Yine eski kazı yerlerinden elde edilen, müze ya da depolarda saklanmıs olan materyelden de yararlanılması gerekirdi.

Fakat, tüm istenilebilir önlemlerin yerine getirilmiş olmaș için hangi tip örnekliklerin seçilmesi gerektiğini, hangi güvenceyi verdiklerini, seçenek olması durumunda hangi materyelin seçilmesi gerek-

J. Evin, Critères de choix des échantillons pour la datation par le radiocarbone. Bulletin de la Société Prehistorique Française tom 74, no. 5-Mai, 1977. 
tiğini bilmek gerekir. İşlemin kendisi başlamadan önce örnekliğin karşısında takınılan bu inceleme tavrı, elde edilen tarihin geçerliğini büyük ölçüde belirler ve boşuna bir önlemle zaman kaybetmeyi önler.

Elverişli tüm örneklik tiplerinin tam bir kritiği için tamamlayıcı 4 yaklaşımın yapılmış olması gerekir. Gerçekten de daima, yalnızca yataklar içindeki örnekliklere etki eden kimyasal bozulmaları düşünerek incelemeyi sınırlandırma eğilimi vardır. Gerçekte karbonlu maddenin özel yapısı jeofizik problem için temel teşkil eder ve $\mathrm{C}_{14}$ yönteminin özündedir. Kısacası, örnekliğin kazı sırasında toplanmasında olduğu kadar, yatakların oluşumu sırasında örnekliğin yerine yerleşmesinde de karşımıza çıkabilecek beklenmedik olayları geçiştirebilmek için, diğer yönleriyle de yetkin olan bir örnekliğin önce jeolojik, daha sonra arkeolojik geçerliliğinin incelenmesi de gereklidir.

\section{I- Jeofizik Kritik:}

$\mathrm{G}_{14}$ yönteminin iyi bilinen gerçeklerinden biri yaşlandırılacak örnekliğin "canlı iken" atmosferin karbonik gazı ile denge halinde olması gereğidir; bir başka deyişle, $\mathrm{C}_{14}$ 'deki orijinal radyoaktivitesi atmosferinkine eşit olmalıdır. Bu koşul hemen hemen tüm hayvan ve bitki kökenli örnekliklerde yerine getirilmiştir. Kimi kez laboratuvar yalnızca izotopik parçalanmanın ufak bir incelenmesini uygulamak zorundadır (Lermann, 1973). Şu halde odun kömürleri, yanmıs ya da yanmamış kemikler, odunlar ve turblar bu açıdan iyi örnekliklerdir.

Buna karşın, karbonatlaşmı̧̧ örneklikler için sorun daha karmaşıktır. Bunlar için oluştukları ortamı incelemek gerekir.

- Denizel organizmalar: Bunlar deniz suyu içinde çözülmüş karbonat ve bikarbonattan başlayarak kabuklarından karbonat oluştururlar. Oysa, bazı nedenlerden ötürü (kara sularının getirdikleri, buharlaşma, yüzey suları katmanlarıyla bağdaşı oımayan karışma) $\mathbf{C}_{14}$ 'ün bu bikarbonattan tutuluşu atmosferinkinden farklıdır ve türlere göre karbonun bünyeye sindirilmesinin çeşitleri de olabilir. Kabuklu deniz hayvanlarından elde edilmiş $\mathbf{C}_{14}$ yaşlandırmalarının yorumu için bu olayların sonuçları son ylllarda çözümlenmiştir (Thommeret, 1976). 
- Karasal yumuşakçalar: Bunlardan su dışında yaşayanlar (özellikle Helix'ler) dikkate alınmalıdır. Bunlarm kabuklarının karbonu ancak atmosferden elde edilir. $O$ halde bu tek jeolojik görünüm altında, kuramsal olarak iyi örnekleri oluşturma olasilıkları vardır. Buna karşın, nehir ve göl suları içinde yaşayan tüm yumuşakçalar karbonu ancak suda bulunan karbonik gazdan çekip alabilirler ve bu, hiç kuşkusuz ki, atmosferinki ile kimyasal ve izotopik dengede değildir. Şu halde, bu sonuncu kabuklardan elde edilmiş yaşlandırmalara güvenmemeli hatta onları atmalıdır.

- Çeşitii kalker tortullar: Bunlar tüfler, kalker yumrular, göl ya da denizkulağı tebeşirleri ve sarkıt ya da dikit tabanlarıdır. Bu depoların oluşmalarının fiziko-şimik koşulları oldukça karmaşı olup, zaman zaman da iyi bilinmemektedir (dikitlerde olduğu gibi). Şu halde elde edilen yaşlara güvenilemez. Bazı ayrıklayıcı durumlar bunun dışında kalır: Yalnızca çok yaklaş̧k yaşlandırmada yararlanılabilen kalkersiz ülkelerin gölleri (Delibrias et Dutil, I966): Tortullar içindeki tabaka arası tüfler gibi (Vita-Fenzi, 1974).

Böylece, örnekliklerin çeşitli tiplerinin jeofizik kritiği, içlerinden bazılarını değerlendirmeyi ve diğerlerinden de sakınmayı gerektiriyor. Şayet bu sonuncuları kullanma zorunluğu varsa, yaşlandırmaların çoğaltılması dilenebilir, ancak bundan çok büyük bir kesinlik beklemek de aldatıcı olabilir.

\section{II- Kimyasal Kritik:}

Bundan önceki kritik, karbonlu materyellerin oluşmaları anındaki değeri üzerine dayanıyordu; şimdi ise, kısa ya da uzun süreler boyunca katmanlar içinde saklandıktan sonra niteliklerini koruyup koruyamadıklarını görmek gerekir. Bir başka deyişle, bunların karbonlu ilk yapılarının elenemeyen bozulmalarla önüne geçilemeyecek şekilde etkilenip etkilenmediklerini ya da içlerinde bulundurdukları karbonun çok azalıp azalmadığını sormak gerekir.

Yaşlandırmalarda kimyasal bozulmaların önemini anlayabilmek için, kalıntısal $\mathrm{C}_{14}$ radyoaktivitelerinin çoğu kez, özellikle çok sayıdaki bozucu etkeninkilere kıyasla, çok zayıf olduğunu hatırlamak gerekir. Öte yandan da birinin diğerleri üzerindeki göresel etkileri daha önce kesin olarak belirtilmiştir (Delibrias et Giot, 1970). 
Bununla birlikte laboratuvarlar, bozulmaları elemeye olanak sağlayan, fakat her tip materyele uygulanamayan, örnekliğin hazırlanması tekniklerini düzenlediler. Şu halde bunların geçerliliği, onlara uygulanabilecek arıtma tekniklerinin geçerliliği ile koşullanmıştır.

3 tip hazırlık olanağı vardır: gerek çok gelişkin kimyasal işlemle (kuvvetli baz ve asitlerin etkisiyle) bozulmaların elenmesi, gerek uygun bir kimyasal işlemle tek ilginç organik materyelin seçimi, gerekse önceki yöntemlerin kullanılmasının olanak dışı olması durumunda, yeterli olabileceğini dileyerek ölçülü bir işlemin geliştirilmesidir.

a) Bozucuların çözülmesi yoluyla maddenin arıtılması: Çok gelişkin kimyasal işlem, kimyasal olarak en devinimsiz karbonlu maddenin elde edilmesine olanak sağlar. Bu, büyük odun kömürlerine ya da oduna çok iyi uygulanır, ancak iyice bilmek gerekir ki, kökler ya da zarar verici topraksal maddeler bulundukları doğal ortam içinde (in situ) çok kalımlı bir duruma geiinceye kadar gelişebiiirler. Şu halde, kuvvetli bir işlemle bunları elemek başarılamayacaktır. Bu yüzden toz halinde karbondan oluşmuş örneklikler (kömürlü toprak, kül) güvenilir sonuç vermezler. Tărihler çoğu kez erkendir. Her nekadar, arkeolojik yerleşme yerinde kendisinden yararlanılabilir tek örnek olsa da, son derece sakınılacak bir tiptir.

b) Organik maddenin ayıklanması: Eğer ilginç karbonlu madde kimyasal olarak az kalımlı ise, onu iyi bir ayıklama işlemi ile örnekiğin bütünlüğünden ve bozucularından çekip çıkarmak olanakl1dır. Diğer yönlerde yapılan çok sayıdaki deneylerden sonra, sonuç olarak kemikler için şimdi en çok uygulanan bu ayıklama yöntemidir (Longin, 1971). Asitli suda bütün mineralli kısımları çıarıldıktan sonra, eski kemiklerin kollajen (yapıskan) maddesi ayrılır, yaşlandırma için geçerli olan tek kısmı elde etmeye olanak sağlayan bu işlem çok iyi sonuçlar verir ve kemikler en iyi yaşlandırma materyellerinden biri durumuna girer (kazı sırasında markaj verniklerinin ya da koruyucu maddelerin içine sızmasıyla, önüne geçilemeyecek bir şekilde bozulmamıs olmaları halinde).

c) Ölçülü işlem: Bazı durumlarda kuvvetli kimyasal işlem sonuna kadar geliştirilemez; çünkü, bazı örneklikler tamamen parçalanmak tehlikesiyle karşı karşıya kalır. Şu halde bozulmayı içerdiği umulan kısmın çözülmesinden sonra işlem istiyerek durdurulur. 
Yatakların şekli bozucuların hareketini önlediği oranda bu ölçülü işlem yeterlidir. Buna karşın, tortulların su geçirgenliğinden ötürü bozulmalara çok elverişli fosil zeminler için yalnızca bu kısmî işlemin uygulanabilmesi, onları özellikle yaşlandırma için tehlikeli k1lar, son derece uygun durumların dışında (volkanik akıntılar altındaki zeminler; Brousse et al., 1970). Nihayet bütün kabuklar, kalkalker yumrular için kimyasal asit işleminin ancak kısmî olabileceği anlaşllyor. Şu halde bozulma varsa, bunun ancak yüzeysel kimyasal ya da izotopik bir değiş tokuş olduğunu varsaymakla yetiniliyor. Ve örnekliğin üst tabakalarının giderilmesinin yeterli olacağ umuluyor. Burada, karbonatlı maddelerin yaşlandırılmasında bir başka zorluk görülüyor ki, bu da, özellikle kabukları çok ince olan ve içleri zorlukla temizlenebilen mikro-yumuşakçalarla ilgili durumdur.

\section{III- Jeolojik Kritik:}

Örnekliklerin yataklarmın durumlarını ayrıntılarıyla işlemek böyle bir makalenin konusu değildir. Burada yalnızca "sapkın" denilen yaşlandırmaların büyük çoğunluğunun nedeni olarak unutulduğu, deneyde ortaya çıkan bazı jeoloji ilkelerini hatırlatmakla yetinilecektir.

$\mathrm{Bu}$ ilkelerin en açığı, örnekliğin tüm elemanlarının stratigrafik durumunun en iyi şekilde bilinmiş olmasıdır. Daha küçük, ama daha arı bir örneklik, geniş alanlardan elde edilmiş çok sayıda, gerçekte bozulma ya da stratigrafik yanılgı teblikesini fazlalaştıran materyelden herhalde daha üstündür. Kazıların kazılmış toprakları içinde yüzeyden toplanan, ya da müzelerdeki -ki bunlar çoğu kez çok iyi örneklikler verseler bile- örneklikler için de aynı şey sözkonusudur.

- En güvenilir örneklikler katmanlarm ortalarından elde edilir: daha küçük ve çok nitelikli olmayan bir örneklik, çok iyi olan, ama katmanın sınırında ya da stratigrafik katmanın eğimli kesiti içindeki bir örneklikten daha iyidir.

- Çok sayıda değişiklik oluşturma nedenleri vardır (yeraltı yuvaları, direk delikleri, sel sularının açtığı yarıklar, devinimli toprakta ağırlıkla göçme): bu nedenlerin küçük öğeleri daha çok etkileme şansları vardır; ama bazı büyük parçalar da kuraldışı olarak yer değiştirmiş olabilirler. 
Kökler genellikle düşünüldüğünden çok daha derine inicilerdir; yatay olduğu kadar dikey bir plân içinde de gelişmiş olabilirler. Öte yandan, katmanların düzlemlenmesi işleminde yokmuş gibi görünebilirler, bu onların diğer evrelerde çok olmadıkları ve katmanlar içinde çıplak gözle görülemeyen küçük kökçüklerin büyük bir sayıda kalmadığı anlamına gelmez. Sonuçta, uzun süreden beri açık havada kalmış belirtileri içinde onların geli̧̧mesini göz önünde bulundurmak gerekir.

Bütün bunlar ancak arazide rastlanabilecek bazı güçlüklerdir ve çoğu kez yanılgı nedenleri, yalnızca kazı yapan kişi ile laboratuvar arasındaki karş̧lıklı bir tutarlık ilişkisi ile bulunup, ortaya çıkarılabilir. Bu nedenle, yaşlandırma amacıyla gönderilmiş örnekliğin yatak şekli üzerinde büyük ölçüde bilgi ve*ilmesi salık ve"ilmiştir (Delibrias et Evin, 1972).

\section{IV-Arkeolojik Kritik:}

Sonuçların yorumlanma biçimi z̧ibi (Deıibrias et a:., I976), radyokarbonla yaşlandırılmaya ay"ılmış nesnelerin arkeolojik tipik örnekliliği daha önce iyice incelenmiştir (Waterbolk, 197ı). Burada yalnızca iki önemli sorunu hatırlatmak uygundur. Bir taraftan nesnenin görünüşteki yaşı, öte yandan yeniden kullanımı sorunu.

- Görünüşteki yaş: Odunda yalnız dış kısım canlı olduğundan, eğer ağacın içi ölçülürse, onun kullanımı değil, ancak gelişmesinin başlangı̧̣ yaşının elde edilebileceği söz konusudur. Bunun eski diptarih için önemi yoktur, ama belki yakın geçmişteki evreler için önemlidir. Çünkü, burada bir kalasın yaşı ile büyük bir yapının yapım yaşı, hatta onarım yaşı arasında örneğin ıoo ile 1 jo senelik bir süre olabilir.

- Yeniden kullanımı: Çeşitli materyelin ikinci derecede kullanım örnekleri çoktur. Bu, yakacak olarak yararlanılm'ş odunların durumudur. Yine taş sandukaların yeniden kullanılması, fosil nesneler de düşünülebılir. Bütün bu durumlarda hiç kuşkusuz ki yaşlandırma, beklenen yaştan tamamen farklı olacak, ama önemli bir bilgi taşıacaktır. 


\section{Sonuç:}

Olurlu çeşitli görünümler altında yapılmış olan örneklikler kritiği bütün materyel tiplerini gözden geçirmeye olanak sağlads. Yazınin sonundaki tabloda, tüm etkenleri göz önünde bulundurarak, daha önceki düşünceleri kısaca özetliyoruz.

Hiç kuşkusuz ki, bütün katman ve arkeolojik problemler için genelleme yapmak tehlikeli olabilir, fakat biz yalnızca birkaç genel bilgi vermek istedik: Her buluntu yerine özgü tüm problemlerin en iyi șekilde çözümlenebiimesi için jeolog, arkeolog ve yaşlandırma laboratuvarları arasında en büyük bilgi alış-veriş isişkisinin varolması özellikle istenilecek bir durumdur.

\begin{tabular}{|c|c|c|c|}
\hline $\begin{array}{l}\text { Karbon ile yasslandırıl- } \\
\text { mak için önerilmis kar- } \\
\text { bonlu örnekliğin yapısı }\end{array}$ & $\begin{array}{l}\text { Iyi koşullarda } \\
\text { bir yaşlandır- } \\
\text { maiçin gerekli } \\
\text { ağırlik }\end{array}$ & $\begin{array}{l}4 \text { kritik sonucu } \\
\text { genel değer- } \\
\text { lendirme }\end{array}$ & Açıklamalar \\
\hline $\begin{array}{l}\text { Iri odun kömürleri ( } 1 \mathrm{~cm} \\
\text { nin üstünde boy) }\end{array}$ & Io $\mathrm{gr}$. & Ùstün & $\begin{array}{l}\text { Kölkçüklerle tam bir içe } \\
\text { sokuluş dişında }\end{array}$ \\
\hline Odun $\ldots \ldots \ldots \ldots$ & $20 \mathrm{gr}$. & Üstün & Aynı \\
\hline Kemikler .. & $\begin{array}{l}\text { I } 00 \mathrm{gr} \text {. ile I kgr } \\
\text { arası }\end{array}$ & Ưstün & $\begin{array}{l}\text { Fakat organik maddenin } \\
\text { düzensiz saklanımı }\end{array}$ \\
\hline Turblar & $5^{\circ}$ gr. kuru & Çok iỵi & $\begin{array}{l}\text { Su geçirgen alanda yalı- } \\
\text { tık düzey olması halinde } \\
\text { tehlike }\end{array}$ \\
\hline Kabuklar $\quad \ldots \ldots \ldots$ & $30 \mathrm{gr}$. & iyi ya da kötü & $\begin{array}{l}\text { Köken ortamina uygun } \\
\text { olarak }\end{array}$ \\
\hline Kalker yumrular & $100 \mathrm{gr}$. & Bazı kez iyi & ayn 1 \\
\hline $\begin{array}{l}\text { Fosil zeminlerin organik } \\
\text { maddeleri } \ldots \ldots \ldots \ldots\end{array}$ & $\begin{array}{l}\text { G'nun \% sine } \\
\text { göre }\end{array}$ & $\underset{\text { iyj }}{\text { Ender olarak }}$ & $\begin{array}{l}\text { Karmașı işlem ve henüz } \\
\text { az emin }\end{array}$ \\
\hline Kömürlü topraklar & $\begin{array}{l}\text { C'nun } \% \text { sine } \\
\text { göre }\end{array}$ & Kötü & $\begin{array}{l}\text { Bozucularm elenmesinde } \\
\text { kesinlik yok. }\end{array}$ \\
\hline
\end{tabular}

\section{BAŞVURU}

Brousse R., Delibrias G. et Labeyrie J. (I970).- Utilisation des sols fossiles sous scorie pour la datation par le Carbone $\mathrm{I}_{4}$ du zolcanisme. Bull. volc., 34, pp. 254-26o.

Delibrias G. et Dutil P. (1966). Formations calcaires lacustres $d u$ Quaternaire supérieur dans le Massif Central saharien (Hoggar) et datation absolues. C.R. Acad. Sc. Paris, Ser. D, pp '262. 55-58. 
Delibrias G. et Evin J. (1972). Remarques à propos des demandes d'analyses par le Carbone I4 et l'interprétation de leurs résultats. Bull. Soc. Prehist. Fr., 69, C.R.S.M. no 6, pp. 189-192.

Delibrias G. et Evin J. ( $1974-75)$. Sommaire des datations Carbone I4 concernaant la Préhistoire en France I, Dates parues de 1955 ̀̀ 1974. Bull. Soc. Prehist. Fr., 71, C.R.S.M. no 5, pp. I49-156; 72, C.R.S.M. no 3, pp. 93-96 et 72 C.R.S.M. no 9, p. 277-288.

Delibrias G., Evin J. et Thommeret J. et Y. (1976). IX conférence internationale du Radiocarbone et correction des dates i 4 C. Bull. Soc. Prehist., 73, C.R.S.M. no 9, pp. 268-269.

Delibrias G. et Giot P.R. (1970). Inadéquation, hétérogénéité et contamination des échanges soumis pour les datations radiocarhone. Bull. Soc. Prehist. Fr., 67, C.R.S.M. no 5, pp. I $35^{-1} 37$.

Delibrias G., Guillier M.-T., Evin J., Thommeret J. et Y. (1976). Datations absolues des dépôts quaternaires et des sites préhistoriques par la méthode du is C. La Préhistoire Franģaise, vol. I, appendice, pp. I499-I514. C.N.R.S. edit.

Delibrias G., Guillier M.-T., Evin J., Thommeret J. et Y. (1976). Datations absolues des dépôts postglaciaires et des gisements pré et protohistoriques (Néolithique, Age du Bronze, Age du Fer) : La Prehistoire Française, vol. II, appendice, pp. $857-899$. C.N.R.S. edit.

Evin J. (1976). Problèmes posés par lo datation $1_{4} C$ des os. Colloque "Datations absolues et analyses isotopiques en Préhistoire. Méthodes et limites". IX ${ }^{e}$ congrès U.I.S.P.P., Nice, Sept. 1976, prétirage, pp. 63-8I.

Evin J. (1977). Réflexions générales et données nouvelles sur la chronologie absolue ${ }_{14} C$ des industries de la fin du Paléolithique supérieur et du début du Mésolithique. Colloque intern. C.N.R.S. "La Fin des temps glaciaires en Europe", Bordeaux, mai 1977, à paraitre.

Lerman J.-C. (1973)., Carbon dating: origin and correction of isotope fractionation errors in terrestrial living matter. Colloque intern. C.N.R.S. "Les Méthodes quantitatives d'étude des variations du climat au cours du Pleistocène", Gif, Juin 1973. 
Longin R. (1970). Extraction du collagène des os fossiles pour la datation par la méthode du carbone $\mathbf{1} 4$. Thèse 3 e cycle, Univ. Lyon no 553, $70 \mathrm{p}$.

Thommeret J. (1976). Difficultés d'intérprétation des dates i4 $C$ mesurées à partir des coquilles marines. Colloque "Datations absolues et analyses isotopiques en Préhistoire. Méthodes et limites". IX ${ }^{\mathfrak{e}}$ congrès de L'U.I.S.P.P., Nice, Sept. 1976, prétirage, pp. I68-169.

Vita Funzi C. Age of valley deposits in Périgord. Nature, 250 , no 5467 , pp. $568-57$.

Waterbolk H.T. (1971). Working with radiocarbon dates. Poroceed Prehist Soc., 37, pp. 15-33. 